\title{
¿Qué canta y baila, corta y vuela, y viene del norte a la vez? El flamenco: un complejo problema de homonimia/polisemia
}

\author{
LIEVE VANGEHUCHTEN \\ Dpto. de Comunicación Empresarial Internacional \\ Facultad de Ciencias Económicas Aplicadas \\ Universidad de Amberes
}

\section{RESUMEN}

Según el Diccionario crítico etimológico castellano e bispánico de Corominas y Pascual (1980: 906), la etimología de "flamenco" en sus acepciones de "ave zancuda" y "arte del cante y del baile de la Andalucía gitana" es "flamenco, nativo de Flandes", debido a la supuesta semejanza con la tez coloradota y encarnada de este último. A pesar de ello, varios argumentos lingüísticos, históricos, antropológicos y musicológicos nos inclinan a rechazar dicha etimología y a proponer otra, basada esencialmente en la oposición homonimia/polisemia y en la acepción de "cuchillo de Flandes" en el español de Andalucía.

Palabras clave: Flamenco, Etimología, Homonimia, Polisemia, Metáfora, Metonimia.

\section{SUMMARY}

According to the Diccionario crítico etimológico castellano e hispánico, by Corominas \& Pascual (1980: 906), the etymology of "flamenco" in its meanings of "flamingo" and "music and dance of Gypsy Andalusia" is "Flemish, native of Flanders" because of the supposed resemblance to the latter's ruddy and reddish complexion. However, a number of linguistic, historical, anthropological and musicological arguments persuade us to reject such explanation and propose an alternative one instead, based on the opposition homonymy/polysemy and on the meaning of the phrase 'flemish knife' in Andalusian Spanish.

Key words: Flamenco, Etymology, Homonymy, Polysemy, Metaphor, Metonymy.

RDTP, LIX, 2 (2004): 127-143 
LIEVE VANGEHUCHTEN

\section{INTRODUCCIÓN}

En este artículo se examina críticamente la etimología de 'flamenco' en sus acepciones de 'ave zancuda' y 'arte del cante y del baile de la Andalucía gitana' tal como la propone el Diccionario crítico etimológico castellano e bispánico de Corominas y Pascual (1980: 906). Varios argumentos lingüísticos, históricos, antropológicos y musicológicos obligan a cuestionar el proceso de una mera extensión metafórica del 'flamenco, nativo de Flandes' a partir de la supuesta semejanza con su tez coloradota y encarnada, y nos inclinan a formular una etimología más matizada, basada esencialmente en la oposición homonimia/polisemia y en la acepción de 'cuchillo de Flandes' en el español de Andalucía.

\section{El AVE ZANCUDA Y EL NATIVO DE FlaNDES: UN CASO DE HOMONIMIA}

A la homonimia léxica se llega a través de un proceso de confluencia fónica de dos formas distintas cuyos significados no presentan intersección. Esto es, en nuestra opinión, el caso de flamenco en sus acepciones de 'nativo de Flandes', por un lado, y 'ave zancuda', por otro. En su primera acepción deriva de flaming, la forma predecesora (primera atestación en 883, Woordenboek der Nederlandsche taal 1971: 1473) de la actual vlaming. Según Corominas y Pascual (ibid.) es este 'flamenco' el que constituye la base de la denominación del ave por una extensión metafórica en la que el tertium comparationis sería el color rojo. Hay otras hipótesis que se basan igualmente en un rasgo compartido entre los nativos de Flandes y el ave, como por ejemplo la que encontramos en Shipley (1945: 153):

[...] the bird may have been named in mockery of the bright clothes of the Flemings.

Más probable que esta polisemia basada en supuestas semejanzas de físico o indumentaria con el nativo de Flandes, nos parece la siguiente hipótesis homónima. En romance, antiguo provenzal, existe la forma flamenc, que significa 'color de llama, rojo' (Mistral 1966: 1142). Esta forma proviene del latín flamma en combinación con un sufijo teutónico '-enc' (Trésor de la langue française 1980: 937). La misma forma evolucionó semánticamente en provenzal hacia el ave (con alas) de color de llama. También en griego, y de ahí en latín, se utilizaba la referencia al color de las alas para denominar el ave: phoenicopterus, literalmente 'con 
alas de color rojo púrpura'. En catalán ${ }^{1}$ existe la misma forma, flamenc, con el mismo significado, por lo cual una evolución morfológica parecida en castellano es, sin lugar a dudas, posible, como tampoco niegan Corominas y Pascual (ibid.).

No obstante, según Corominas y Pascual (ibid.), esta hipótesis "es poco convincente desde el punto de vista semántico-estilístico" porque "un derivado *flamenc no es imposible que significara 'color de llama', pero no es probable como denominación popular". Sabiendo que la lingüística cognitiva ha demostrado que la metáfora y la metonimia, no como figuras estilísticas de la retórica sino como mecanismos conceptuales creadores de significado, forman la base de la polisemia ${ }^{2}$, es imposible pretender que una metáfora no puede tener origen popular ${ }^{3}$. Además, si Corominas y Pascual sugieren la lexicalización de una relación metafórica rebuscada de color entre el natural de Flandes y el ave, la hipótesis de que se ha recurrido a la imagen de la llama para expresar los matices en el plumaje rosado con toques escarlata y púrpura, no parece menos aceptable, tanto más cuanto también en griego y en latín la denominación es el resultado de una extensión metonímica popularizada. Otro argumento que aportan los etimólogos españoles es el nombre de la protagonista del poema medieval provenzal "Roman de Flamenca". 'Flamenca' es en esta obra anónima de ca. 1270 una mujer provenzal, famosa por su hermosura, que discute violentamente con su marido y comete adulterio. Ahora bien, como las flamencas son prototípicamente "de buenas carnes, cutis terso y bien coloreado", según los etimólogos españoles (ibid.), "lo más verosímil es también que la heroína del poema occitano [...] recibiera este nombre por la misma razón, en contraste con el cutis más pálido de las provenzales". Para personas nórdicas, resulta curioso leer que las provenzales son más pálidas que las flamencas, ya que solemos asociar la palidez con la gente del norte y el cutis coloreado, o sea moreno, con la gente del sur. Teniendo en cuenta que la percepción de la tez de los nórdicos en oposición con la gente del sur parece estar culturalmente determinada, esta cita no aporta una prueba decisiva.

\footnotetext{
${ }^{1}$ En Cataluña hay flamencos en el delta del Ebro y en Andalucía en las marismas del Guadalquivir (Nueva Enciclopedia Larousse 1984: IV, 4002).

${ }^{2}$ Como dice Dirven (2002: 38) con una boutade: "In the beginning was the word, and then came metonymy and metaphor".

${ }^{3}$ Ya en latín existía el adjetivo de color flammeus, que significaba 'con color de llama' (André 1949: 115).
} 


\section{El ARTE ANDALUZ Y EL NATIVO DE FlaNDES: UNA POLISEMIA COMPLICADA}

La polisemia es el resultado de un proceso de diversificación semántica. Cuando hay cercanía significativa o intersección de distintos significados, hablamos de polisemia. En la polisemia se pueden distinguir polisemias por extensión o por especialización de significado, metonimias y metáforas (el continuo conceptual literal-figurativo de Dirven 2002: 107). Corominas y Pascual (ibid.) basan la etimología de 'flamenco' como cante y baile de origen andaluz principalmente en la evolución semántica de la metáfora de "los colores vivos", o sea, la semejanza física del nativo de Flandes con el andaluz agitanado y de ahí, por la metonimia productorproducto, al cante y baile de éste último. En lo que sigue, podremos ver que hay otras relaciones semánticas que vinculan estos conceptos.

\subsection{Estado de la cuestión}

Aparte de la etimología propuesta por Corominas y Pascual, existen muchas más hipótesis: Álvarez Caballero (1981: 134-143), por ejemplo, recoge en total doce. Presentamos a continuación las más importantes, ya que aportan elementos interesantes a la formulación de la nuestra.

\section{a) La hipótesis árabe}

Según esta hipótesis 'flamenco' es una homonimia derivada del árabe fellab mengu(s), lo que significaría cante del campesino. Aunque esta tesis se puede defender sabiendo que en 1492 muchos árabes se mezclaron a la población gitana, se plantea un problema en cuanto al tiempo. El término surge sólo a partir del segundo tercio del siglo $\mathrm{XIX}^{4}$, por lo cual esta hipótesis resulta poco probable. Además, los musicólogos estiman que el aporte de la música árabe al flamenco es mucho menos importante de lo que se pretende. El flamenco es el resultado de una tradición musical hispano-andaluza —que ya contenía elementos árabes, judíos y litúrgicos bizantinos - forjada por los gitanos de la Baja Andalucía con sus propias estructuras melódicas y rítmicas para crear el cante jondo (Leblon 1990, 1991, 1995; Jamard 2001). Sin los gitanos de la Baja Andalucía no hubiera

${ }^{4}$ Álvarez Caballero (1981: 134) cita una tonadilla de 1830 en que se encontraría la primera atestación de 'flamenco' como sinónimo de gitano y su lenguaje. 
existido el flamenco, y el hecho de que la letra de los cantes y la literatura del siglo XIX (Pardo Bazán, Valera, Pérez Galdós, Clarín, Blasco, Ganivet ${ }^{5}$ ) utilizan 'flamenco' como sinónimo de 'gitano andaluz' o 'andaluz agitanado' antes de designar la música, aporta otro argumento para descartar la hipótesis árabe.

\section{b) La hipótesis de la capilla flamenca}

Tanto los flamencos como los gitanos y los árabes hacían música en las cortes españolas. No obstante, después de la expulsión de los árabes, subsistían únicamente los flamencos y los gitanos (Jamard 2001: 79). Por la fama que tenían los flamencos de ser buenos cantores, se puede haber aplicado esta denominación a cualquier cantor competente. Asimismo, Jamard (2001: 81) señala que según las fuentes literarias los gitanos solían interpretar a su manera las danzas y melodías españolas de moda, y es esta mezcla, con otras influencias más, la que constituye el material de base del flamenco:

séguedilles, chaconnes, sarabandes, etc., accompagnées au tambour de Basque, au cadre à cymbalettes, au psaltérion, au luth, aux castagnettes ...

Pero, aquí se plantea una vez más el problema del tiempo: ¿por qué no surge la denominación hasta tan tarde, cuando la capilla flamenca data del siglo XVI? Además, en Cervantes (1615: 820) encontramos una referencia indirecta a la música flamenca y la de los gitanos, y las opone claramente:

Aquél que no es nada renco/ se llama Diego Mostrenco;/ el otro Gil el Peraile;/ cada cual diestro en el baile/ como gozquejo flamenco./ Tocándoles Pingarrón,/ mostrarán bien su destreza/ a compás de cualquier son,/ y alabarán la agudeza/ de nuestra nueva invención./ Las danzas de las espadas $6 /$ hoy quedarán arrimadas,/ a despecho de hortelanos,/ envidiosos los gitanos,/ las doncellas afrentadas./ ¿No le pareció, señor,/ muy bien el talle y el brío/ de uno y otro danzador?

c) La hipótesis jergal (Salillas 1896: 218)

La hipótesis es que, cuando Carlos III ordenó la integración de los gitanos, éstos se unieron a los ladrones, los llamados germanos, que ha-

\footnotetext{
5 Esto se puede comprobar fácilmente consultando la base de concordancias de la Real Academia, CORDE, en http://corpus.rae.es

6 "La danza de espadas es una danza de cascabeles interpretada por hombres exclusivamente, 'donceles', normalmente 24 en total'. (Salazar 1961: 181)
} 
blaban un dialecto de germanía. Igual que éstos últimos, los gitanos querían encontrar un nombre que incitara al equívoco y al disimulo, al mismo tiempo que a un contenido de fortaleza e inteligencia, evocado por la asociación de 'flamenco' con la palabra 'llama'. No obstante, la existencia de una lengua gitana, el caló, pone en tela de juicio esta tesis: ¿Por qué habían de utilizar una palabra castellana si disponían de su propia lengua secreta? ¿Por qué no figura la palabra 'flamenco' en los diccionarios y testimonios escritos de 'caló', una jerga casi desaparecida hoy en día (Ropero Núñez 1978: 56)? Hill (1949: v), quien estudió las voces germanescas en español, concluye que la germanía es una lengua "que nada tiene que ver con el gitanismo y que dejó de existir hacia mediados o, a más tardar, hacia fines del siglo XVII ${ }^{7 ”}$. Además, no se debe olvidar que el flamenco es una manifestación artística del andaluz en general, y no exclusivamente del gitano (Leblon 1990, 1991, 1995). Según esta misma lógica el flamenco como lenguaje es un español andaluz con elementos de caló y de germanía (Ropero Núñez 1978: 56).

\section{d) La hipótesis geográfica}

Según esta hipótesis los españoles estimaban que los gitanos venían de Flandes, por lo cual les pusieron tanto a ellos como a sus cantes y bailes el nombre 'flamenco'. La etimología de la palabra 'gitano' rechaza esta tesis, ya que esta voz viene de 'egiptano' en antiguo castellano, o sea nativo de Egipto. El supuesto origen de los gitanos - este pueblo nómada decía provenir de allí - quedaba por lo tanto muy claro, como también lo demuestra un estudio de 1848 de Campuzano sobre el "Orijen, usos y costumbres de los jitanos" (III-V).

\subsection{El papel del cuchillo de Flandes}

\subsubsection{El contexto histórico}

Ante todo es necesario situar algunos hechos en su contexto histórico. La llegada y la presencia de los gitanos en España está documentada desde 1425 (Méndez 2002). Se trasladan en grupos de entre 25 y 125 personas y sus jefes se hacen llamar Condes o Duques de Egipto. Están provistos de salvoconductos de reyes y emperadores que los califican de

\footnotetext{
${ }^{7}$ No todos comparten esta opinión: véase, por ejemplo, Clavería (1951: 18).
} 
peregrinos y les otorgan privilegios y buen trato durante una buena parte del siglo XV. Después de esta etapa de buena acogida comienza la persecución bajo los Reyes Católicos. A partir de entonces los gitanos están considerados como bandidos y ladrones inmorales y se les condena al trabajo forzado, por ejemplo, en las galeras (Jamard 2001: 80, Domínguez Ortiz 1978: 320). Esto acaba solamente en 1783 con la Pragmática de Carlos III, cuando se les exige asentarse en un lugar fijo, servir a un señor y dejar de ser gitanos. No obstante, cabe señalar que en Andalucía - en contra de las Pragmáticas reales y bajo la protección de los andalucesse van instalando desde la segunda mitad del siglo XvI (Leblon 1990: 123).

En segundo lugar resulta imprescindible hablar de la presencia de los flamencos en España, de los contactos que los españoles tuvieron con Flandes, y de la concepción que tenían de esta región y sus habitantes. Cuando Carlos V se hace rey de España (1517), empieza para los españoles lo que sus historiógrafos bautizaron "la tiranía de los cortesanos flamencos" (Parker 1999; Blockmans 1999; Terlinden 1965). A los consejeros del rey - unos borgoñones que derriban la sobriedad de la corte española, unos buitres ávidos de ocupar los puestos más altos y más lucrativos, derrochadores con el dinero español hasta el punto de dejar vacías las arcas del Estado- los españoles los designan con su nombre genérico de "flamencos", lo que se convierte en un insulto.

Pero también después de Carlos $\mathrm{V}$ siguen viniendo muchos flamencos a España. En los siglos XVI, XVII y XVIII España es la "colonia" comercial de Flandes, incluso después de que Flandes deje de pertenecer políticamente a España (1648). Así podemos leer en Lefèvre (1921: 184) que:

la rupture politique entre l'Espagne et les Pays-Bas [....] n'amena en rien la cessation des rapports d'ordre économique qui existaient entre les deux pays. [...] Les produits d'importation et d'exportation, la balance du commerce, la manière de trafiquer avec les colonies d'Amérique, la place primordiale occupée par le trafic espagnol dans l'ensemble du commerce extérieur des Pays-Bas, tout cela est au XVIIIième siècle, identique qu'aux XVIième et XVIIième siècles.

De esta manera, se instalan bastantes comerciantes flamencos en España, sobre todo en Andalucía: Cádiz, Sevilla (Everaert 1973: 708; Stols 1971). Ha de ser que estos flamencos tenían fama de bon vivants y borrachos, porque en Cádiz existe hasta 1855 una calle llamada "Callejón de los Flamencos borrachos". En 1722 esta calle había obtenido el nombre de "Carnicería de los Flamencos", sin duda porque la colonia flamenca de Cádiz se surtía allí, pero como sus parroquianos son gran aficionados al vino, el nombre se adapta rápido.

Pero no salen únicamente flamencos afortunados y adinerados para España, sino también todo lo contrario. Entre mediados del siglo xviII y 
principios del XIX se trasladan 6000 flamencos y alemanes de baja clase social a Sierra Morena y Baja Andalucía (a áreas de Córdoba, Jaén, Sevilla, Cádiz) para poblar estas regiones desiertas (Bernaldo de Quirós 1929; Vaca de Osma 1997: 222). Así Bernaldo de Quirós (1929: 47) se refiere a una tonadilla escénica - un tipo de teatro popular en aquella épocarepresentada hacia 1770-80 en que aparece el motivo de los colonos venidos a España sin dinero ni cultura, como se desprende del siguiente fragmento en que una española vende morcilla a un alemán y sus hijos, que no pueden pagar:

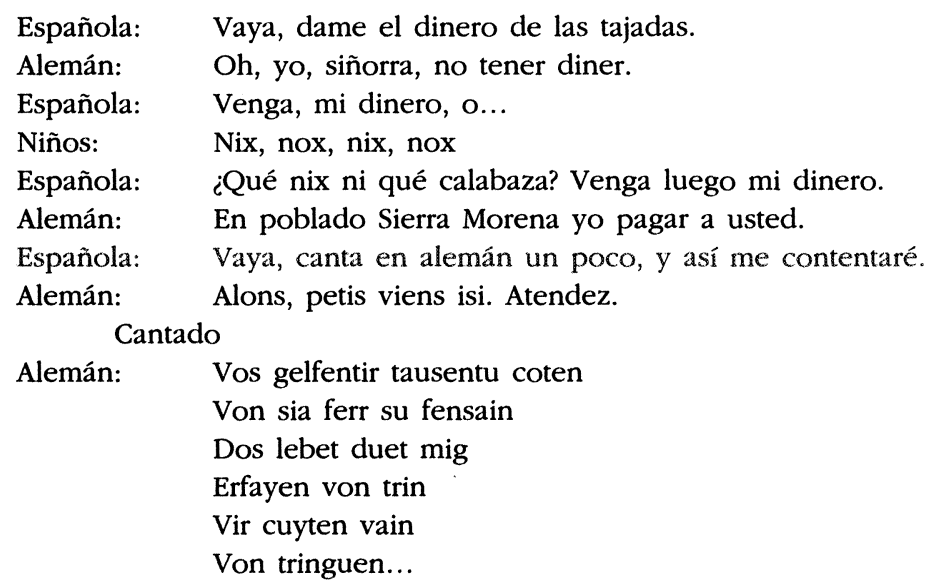

La canción que canta el alemán para pagar su deuda - apuntada en un castellano pseudo-fonético- es claramente una canción báquica, de borrachos $^{8}$. El hecho de que el alemán hable francés con sus hijos, que le contestan en flamenco: nix, o sea niks, 'nada', pero cante en alemán, destaca los diversos orígenes de los colonos: vienen de los Flandes neerlandófonos y francófonos, así como de Alemania.

Aunque la idea inicial es aislar a los inmigrantes flamencos y alemanes para que no entren en contacto con los españoles de las poblaciones antiguas, resulta necesario después de algún tiempo admitir además a españoles, que, desde luego, provienen, a su vez, de las clases sociales más bajas, sin tierra ni posesiones (Palacio Atard 1964: 165-207). Por lo tanto, es muy probable que se deporten también gitanos hacia estas regiones, siguiendo la política de que se sedentaricen (cf., la Pragmática de 1783). De hecho, Leblon (1990: 125) cita exactamente las mismas regiones con relación a los destinos de deportación de los gitanos.

${ }^{8}$ La versión alemana original es sin duda como sigue: "Wass helfen dir tausend Dukaten wann sie versoffen sind. Das leben tuet mich erfreuen von trinnen für guten wein. Von trinken..." 
De lo que precede se desprende que ha habido flamencos en España, y sobre todo en Andalucía, desde el principio del siglo xvI, y que tenían fama de ser más bien unos aprovechados. Asimismo, se sabe con certeza que salen gitanos andaluces para Flandes durante los siglos xvI y XVII, como mercenarios en los tercios. Parker (1978: 61) confirma que cuanto más dura la guerra, tanto más se contrata a personas de las capas más bajas de la sociedad, y que salen tercios andaluces desde Cartagena vía Italia y Alemania. Incluso hay a finales del siglo xvi un tercio con el sobrenombre de "Tercio de la Zarabanda", baile este folclórico de origen andaluz (Parker 1978: 174). Una prueba más directa la suministra Leblon (1990: 123) al referirse a un registro de la población de Alcalá la Real que indica que varias familias gitanas obtienen en 1626 , y no es un caso aislado, la autorización para instalarse como recompensa de su participación en la guerra de Flandes. Los soldados de los tercios de Flandes que no mueren, vuelven a España adinerados y gloriosos, con su propia ideología y moral, predecesores del pícaro español (Parker 1978). Después de una estancia tan larga en Flandes, no extrañaría que se les diera el sobrenombre de 'flamencos', como los 'indianos' que volvieron a España después de haber hecho fortuna en Latinoamérica.

En este recorrido histórico llaman la atención los puntos comunes entre flamencos de Flandes y gitanos. Ya en el siglo XVI 'flamenco' se utilizaba como insulto para designar a la corte de Carlos V. En los siglos posteriores, flamencos de varias capas sociales siguen estando presentes en Andalucía, siempre con fama de 'espabilado, aprovechado'. La hipótesis de que los gitanos, con una reputación parecida, fueron metafóricamente llamados con el mismo nombre de connotación peyorativa, es, por lo tanto, muy plausible. Como dice Geers (1933: 134): "Habrán sido flamencos de baja estofa los que tan poco se distinguían en España de los gitanos, que su nombre pudo aplicarse también a éstos". El hecho de que a partir de 1633 los gitanos ya no puedan ser denominados con este nombre, aún fortalece este razonamiento. Domínguez Ortiz (1978: 322) lee en una consulta del Consejo de Castilla del 4 de marzo del 1633 que "el llamar uno a otro gitano se tenga por palabra de injuria y como tal se castigue, y que ni en las danzas ni en otro acto alguno se permita acción ni nombre de gitano [...]". La Pragmática de Carlos III en 1783 reitera esta prohibición añadiendo el apelativo infamante de "castellanos nuevos", lo cual obligó al uso de 'eufemismos' para designar a los gitanos. Entre estos eufemismos figuran 'morenos', 'gente morena', pero también, 'gente rubia', como antónimo llamativo, y esto acerca el gitano otra vez al 'flamenco de nación' (Torrione 1992: 17) y al uso de su nombre como eufemismo irónico. A partir de ahí la extensión metonímica productor-producto, o sea del gitano a su música, es bastante obvia. 
No obstante, sigue habiendo un problema en el sentido de que el flamenco no es la música del gitano, sino del andaluz en general. Esto significa que en un momento dado se hubo de producir un acercamiento e incluso una identificación de los dos. El 'flamenco' en su acepción andaluza de cuchillo, puede ayudar a desvelar este misterio. ¿Por qué tiene este significado? ¿Y por que sólo en Andalucía?

\subsubsection{El gitano andaluz como ideal romántico}

Leemos en Leblon (1990: 124) que ya antes de la pragmática de 1783 existe una actitud algo más positiva hacia los gitanos en Andalucía en comparación con el resto de España. Esto se manifiesta en la creación de posibilidades para instalarse y ejercer un oficio. Ahora bien, resulta que toda España coge a finales del siglo xviII el gusto por los majos y las majas, la clase plebeya romantizada, representada por Goya en muchos de sus cuadros. En Andalucía (Clavería 1951: 46"), estos plebeyos o majos corresponden a los gitanos ${ }^{10}$, por lo cual los aristócratas andaluces intentan agitanarse apadrinando actividades de cante, baile y toreo. Este afán de identificación con el gitano se manifiesta también en la imitación de su manera de vestir (Torrione 1992: 16): se ponen de moda la capa, la montera y el cuchillo, jun flamenco! ${ }^{-11}$ Varias obras especializadas (Loriega 2001, Martínez del Peral Frontón 1979) afirman que en España en el siglo XIX son muy apreciados los cuchillos y las navajas. No sólo están presentes en la literatura, la poesía, el teatro, las canciones y las coplas burlescas de la época, sino que también se publican varias obras al respecto como, por ejemplo, el Manual del baratero o arte de manejar la navaja, el cuchillo y la tijera de los jitanos de $1849^{12}$ y se pueden observar en varios dibujos y cuadros de Goya.

En Andalucía estaba de moda el flamenco. Este cuchillo debe sin duda su nombre al origen de su artífice. Los flamencos tenían fama de ser buenos cuchilleros, sobre todo los de Malinas (Van Uytven 1991: 46, 152), los de Amberes y Bruselas (siglo xv), y los de Balduque (siglo XvI)

9 Clavería (1951: 22) cita igualmente a Ortega y Gasset, según quien durante todo el siglo XIX España ha vivido sometida a la influencia hegemónica de Andalucía.

${ }^{10}$ De hecho, las pinturas "la maja vestida" y la "maja desnuda", que datan de 1800 , figuraban con el nombre de "gitanas" en el inventario de los bienes del ministro de Carlos IV, Manuel Godoy, que fue su primer propietario.

11 'Flamenco' tiene en Andalucía así como en Argentina hasta bien entrado el siglo XX el significado de 'cuchillo' (Alcalá Venceslada 1951: 278). Ahora el término ha caído en desuso en Argentina.

${ }^{12}$ Del autor sólo se conocen las iniciales: M.D.R. 
(Stroobants 1991: 9). Se sabe con seguridad que se importaban cuchillos flamencos a gran escala desde la segunda mitad del siglo XVI cuando la crisis económica de España culmina. Kamen (1964: 68) cita el relato de un viajero inglés que destaca en 1670 la dependencia española de la industria extranjera de armas blancas y varias fuentes mencionan la exportación frecuente de armas blancas de Flandes a España a partir de 1640 (Cipolla 1965: 34; Stols 1971: 164). También sabemos (Stols 1972: 378) que los flamencos intentaron reanimar, entre otras, la industria de armas blancas en España en esta misma época. Asimismo había cuchilleros españoles que fueron a Flandes a aprender el oficio, como por ejemplo Ángel Herbeira, conocido con el sobrenombre del Borgoñón, que aprendió la cuchillería en Flandes en la segunda mitad del siglo xvil (Rico y Sinobas 1871: 24). Además, el modelo del cuchillo flamenco servía de ejemplo a cuchilleros no flamencos, como corrobora una carta de Domingo Martínez - -español y el primer industrial del Río de la Plata según López Osornio (1942: 9) - enviada en 1556 al rey de España:

Sacra Cesárea Magestad: en la primera habitación de Buenos Ayres, siendo como era venido de España con don Pedro de Mendoza (en 1536), y siendo un pobre estudiante que no sabía oficio ninguno cosa alguna, vista la necesidad que en aquel tiempo había, [...] hice cuchillos amolados y encabados al modo de los que traen de Flandes [...]

Según López Osornio (1942: 10) el origen de los cuchillos importados a Argentina fue Flandes, pasando por Andalucía, y el hecho de que en Argentina 'flamenco' se utilizara como sinónimo de 'cuchillo' lo subraya (López Osornio 1942: 28). En una comunicación personal, un especialista en cuchillería argentina, Abel Domenech ${ }^{13}$, me ha afirmado - entre otras, con una cita de la obra de Estanislao del Campo, autor de literatura gauchesca- que el 'flamenco' era el cuchillo del vaquero argentino, el gaucho:

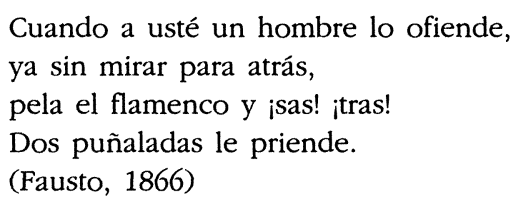

Ahora bien, el oficio más importante de los gitanos ha siempre sido la forja (Domínguez Ortiz 1978: 323, 325; Leblon 1990: 124-126) ${ }^{14}$. Asimis-

${ }^{13}$ Autor de Del facón al Bowie (1988) y El cucbillo táctico (1996).

${ }^{14}$ De hecho, en el documental de Ramón Gieling (El futuro es en una bora, 1997) sobre el flamenco actual, el protagonista es Salvador Vega, un gitano andaluz que trabaja como herrero en Sevilla. 
mo existía una tradición de cante en el taller de forja, como se puede leer en la noticia histórica de Rico y Sinobas (1871: 13):

[...] los artífices templadores cantaban o murmuraban oraciones, algunas fórmulas e invocaciones extravagantes, sin sentido gramatical, a cuyo final se daba por concluida la inmersión y el temple. Estas oraciones, algunos las pronunciaban, siglos atrás, con respeto y cierta gravedad; otros, fijándose en que eran invocaciones, por decirlo así, horológicas, para medir el tiempo de cierto trabajo encomendado al agua, lo hacían con el aire de zumba y burla, tan propia del taller antiguo como del moderno.

Existe todavía un tipo de cante flamenco que se llama "martinete" y que hace referencia al trabajo con el martillo sobre el yunque (Hermans 2001: 95). Asimismo, se dice que el compás, sin el cual no puede haber cante, nació en la fragua, de los golpes en el yunque, y si se habla todavía de "metales de voz", es en este mismo contexto en el que se debe encontrar su origen.

Los andaluces no iban a ningún sitio sin su cuchillo flamenco o su navaja. Esto lo podemos constatar en los textos de las canciones populares y flamencas apuntadas por Machado y Álvarez (1881), Demófilo, o Rodríguez Marín (1883), en que 'flamenco' es sinónimo de cuchillo, pero también de andaluz(a) agitanado(a):

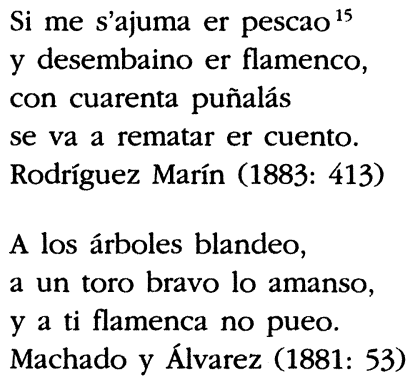

La misma acepción se da en la literatura de la época, por ejemplo, en las Escenas andaluzas de Estébanez Calderón (1846: 60), unos cuadros de costumbres españolas y castizas como él mismo las llamó:

Esto hecho, se desnudaron de las capas con donoso desenfado y desenvainaron para pinjarse cada cual, el uno un flamenco de tercia y media, con cabo de blanco, y el otro un guadijeño de virola y golpetillo, ambos hierros relucientes [...].

${ }^{15}$ Enfadarse, acabarse la paciencia con que se venían oyendo insultos o amenazas (Rodríguez Marín 1883: 424). 
La sinécdoque es obvia: uno era flamenco - gitano y andaluz-, llevando un flamenco. De esta manera se puede decir con Salillas (1896: 219) que a mediados del siglo XIX:

lo flamenco denomina una sociedad, unas actitudes, un modo de sentir, una música y un baile. De un hombre singularizado por su guapeza, presunción y rumbo, se dice que es muy flamenco, y se llama flamenca la mujer que se distingue por una equivalente apostura: hay cante flamenco, comprendidas la música y las palabras, y hay baile flamenco, y en consonancia con todo costumbres flamencas.

Así se emplean en Los majos de Cádiz (1896), una novela de Armando Palacio Valdés, 'gitana' y 'flamenca' indistintamente como piropos para adular a las mujeres andaluzas, y en la novela Toros y cañas. Novela flamenca (M. Fernández y González, Madrid, 1885), 'flamenco' y 'gitano' son sinónimos:

Tú no te has hecho todavía flamenca; pero descuida de que si sigues así por el camino que vas, tú te harás flamencota puratí, y sabrás que los flamencos, esto es, los gitanos, le llaman al verdugo buchí.

\section{CONCLUSIÓN}

Basándonos en todos los argumentos expuestos, podemos esquematizar nuestro razonamiento como sigue:

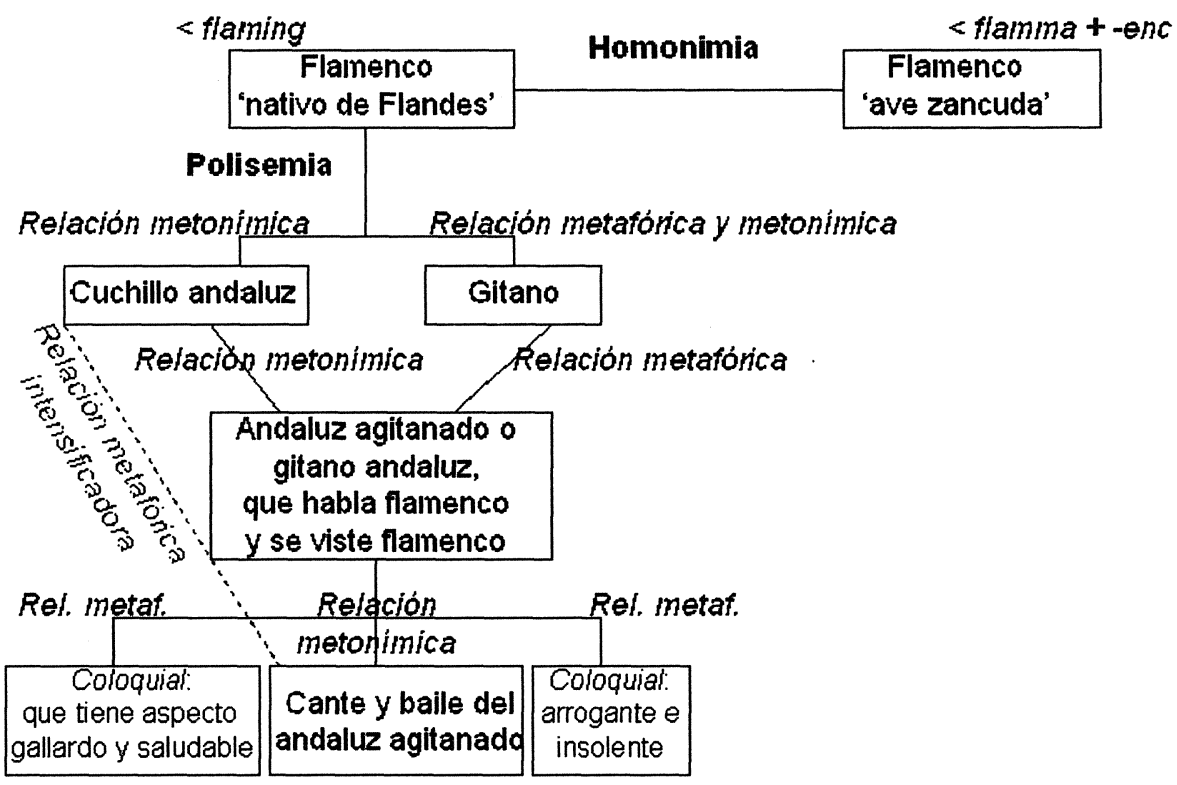


El ave y el nativo de Flandes son formas homónimas. En cuanto a la relación de polisemia entre el flamenco y el gitano, la llamamos metafórica y metonímica a la vez, ya que se debe, por un lado, a la semejanza en cuanto a su reputación compartida de aprovechado, y por otro, a la doble contigüidad espacial. Este gitano se convirtió en el prototipo del andaluz en un momento dado, por lo cual el término 'flamenco' tomó una nueva acepción, la de andaluz agitanado o gitano andaluz que habla flamenco y se viste flamenco, una imagen reforzada por la del cuchillo flamenco, como accesorio metonímico. Y por esta vía se llega a la postmetonimia de 'flamenco' en su significado de cante y baile del andaluz agitanado o del gitano andaluz, intensificada por la relación metafórica con el cuchillo flamenco que evoca la imagen de algo agudo, penetrante y doloroso. De hecho, son numerosas las comparaciones por aficionados del flamenco con un cuchillo y sus características y efectos. Damos unos ejemplos:

- La voz de Menese es sufrimiento puro cuando corta el cante con la agudeza del más afilado cuchillo (sobre José Menese, en www.andalucia.cc/flamenca/ perfilesflamencos/ josemenese.htm)

- El cante de Agujetas es que biere, te sangra, corta las carnes como un cuchillo! A mi cuanto menos, me revuelve el estómago cuando lo escucho cantar (sobre Agujetas, en www.flamenco-world.com/artists/agujetas/agujetas102000/eagujetares.htm)

- En http://www.flamenco-world.com/noticias/ecartbiena.htm:

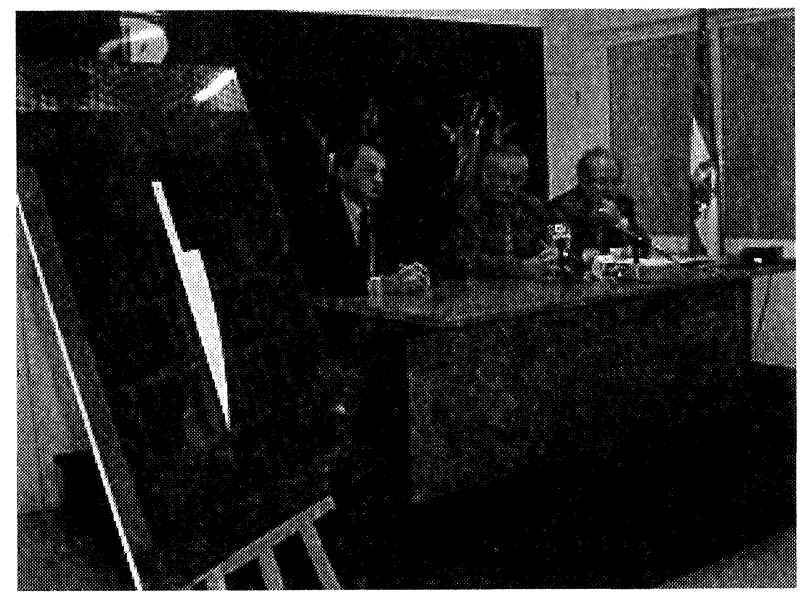

FOTO 1: El cuchillo flamenco

Esta foto representa un austero cartel diseñado por el pintor sevillano Juan Suárez como carta de presentación de la XII edición bienal de fla- 
menco en el 2002. El artista sostiene que su creación representa lo que "me acerca al flamenco". El pintor de la localidad gaditana de El Puerto de Santa María califica su cartel de "escueto, profundo y seco". Sobre fondo azul y con letras negras ha dibujado

una franja blanca, alargada, casi un palillo de dientes que representa la navaja, el cuchillo, la bendidura... una referencia anecdótica al cuchillo flamenco [...] Representa el sentimiento, la pasión y el desgarro, actúa como metáfora del alma que se rasga cuando se deja llevar por el poder de lo jondo.

Concluimos que la etimología de 'flamenco' en sus varias acepciones difícilmente se puede basar en el color rojo de la tez del flamenco, tanto para el ave como para la música gitanoandaluza. De hecho, los testimonios escritos describen la tez de los gitanos más bien de color amarillo, como se puede encontrar, por ejemplo, en Sales Mayo (1870: 7, 41). Ahora bien, es necesario decir que Corominas y Pascual (ibid.) no se limitan al color rojo como tertium comparationis de su metáfora ${ }^{16}$, sino que presentan la evolución semántica en cuanto al cante y baile como sigue: "mujeres de tez sonrosada $\rightarrow$ gallardo, de buena presencia $\rightarrow$ de aspecto provocante, de aire agitanado $\rightarrow$ música agitanada". No obstante, hemos demostrado que hay otros elementos más convincentes que acercan los dos conceptos, como, por ejemplo, el cuchillo.

En definitiva y a pesar de Cervantes que describe a los flamencos con "rostros tan lustrosos" (citado en Corominas y Pascual, ibid.), ¿quién es demasiado rojo como para parecerse a un flamenco y demasiado poco como para parecerse a un flamenco? ¡Claro, el flamenco!

\section{BIBLIOGRAFÍA CITADA}

AlCAlÁ Venceslada, ANTONio. 1951. Vocabulario andaluz. Madrid: Real Academia Española.

Álvarez Caballero, Ángel. 1981. Historia del cante flamenco. Madrid: Alianza.

ANDRÉ, JACQUES. 1949. Étude sur les termes de couleur dans la langue latine. París: Klincksieck.

Bernaldo De Quirós, Constancio. 1986. Colonización y subversión en la Andalucía de los siglos XVIII-XIX. Sevilla: Andaluzas Unidas. (primera edición de 1929, bajo el título, Los Reyes y la colonización interior de España desde el siglo XVI al XIX)

${ }^{16}$ Aunque en el Breve diccionario etimológico de la lengua castellana (1980: 275), se avanza el color rojo como elemento decisivo de semejanza entre el nativo de Flandes, el ave zancuda y el cante andaluz, por lo cual se puede estimar que constituye el núcleo de la comparación. 
Blockmans, WIM. 1999. "De onderdanen van de keizer", en Karel V 1500-1558 De Keizer en zijn tijd: 227-284. Amberes: Mercatorfonds.

CAMPUZANO, RAmón. 1995. Orijen, usos y costumbres de los jitanos, y diccionario de su dialecto. Madrid: Heliodoro. (Edición facsimilar de la de 1848, n.. 2 de la colección "Gitanismo").

Cervantes SaAvedra, Miguel. De [1615]. 1995. Comedia famosa de Pedro de Urdemalas. Alcalá de Henares: Centro de Estudios Cervantinos.

Clavería, Carlos. 1951. Estudios sobre los gitanismos del español. Madrid: García Morato.

CIPOLLA, CARLO M. 1965. Guns and sails in the early phase of european expansion 14001700. London: Collins.

COROMINAS, JOAN. 1980. Breve diccionario etimológico de la lengua castellana. Madrid: Gredos.

COROMINAS, JOAN y JOSÉ A. PASCUAL. 1980. Diccionario crítico etimológico castellano $e$ bispánico. Madrid: Gredos.

Dirven, René. 2002. "Metonymy and metaphor: different mental strategies of conceptualisation", en R. Dirven y R. Pörings R. (eds.), Metaphor and Metonymy in Comparison and Contrast: 75-111. Berlín-Nueva York: Mouton de Gruyter.

-. 2002. "Introduction", R. Dirven y R. Pörings R. (eds.), Metaphor and Metonymy in Comparison and Contrast: 1-38. Berlín-Nueva York: Mouton de Gruyter.

Domínguez ORTIZ, ANTONIO. 1978. "Los gitanos españoles en el siglo XVII", en Homenaje a Julio Caro Baroja: 319-326. Madrid: Centro de Investigaciones Sociológicas.

ESTÉBANEZ CALDERÓN, SERAFín [1846]. 1985. Escenas andaluzas. Madrid: Cátedra.

EVERAERT, JOHN. 1973. De internationale en koloniale handel der Vlaamse firma's te Cádiz 1600-1700. Brujas: De Tempel.

GeErs, Gerardus J. 1933. "Pícaro - Flamenco - Pichelingue”, en Mélanges de philologie: 132-138. Groningue: Wolters.

Hermans, Ivo. 2001. Duende. Berchem: Epo.

Hill, JoHn M. 1982. Voces germanescas. Londres: Ann Arbor. (1 $1^{\text {a }}$ ed. de 1949).

JAMARD, JEAN-LuC. 2001. "Pourquoi le jazz a-t-il si bien tourné? Flamenco, blues: affinités et descendances". L'Homme 58: 73-96.

Kamen, Henry. 1964. "The decline of Castile: the last crisis". Economic History Review XVII: 63-76.

LEBLON, BERNARD. 1990. Musiques tsiganes et flamenco. París: L'Harmattan.

- 1991. El cante flamenco entre las músicas gitanas y las tradiciones andaluzas. Madrid: Cinterco.

—. 1995. Flamenco. París : Cité de la musique Actes-Sud.

LEFÈVRE, JOSEPH. 1921. Étude sur le commerce de la Belgique avec l'Espagne au VIIrème siècle. Bruselas: Lamertin-Hayez.

LORIEGA, JAMES. 2001. Sevillian steel: the traditional knife-fighting arts of Spain. BoulderColorado: Paladin Press.

LÓPEZ OSORNIO, MARIO A. 1942. Esgrima criolla. Buenos Aires: El Ateneo.

MACHADO Y ÁlvareZ, ANTONIO. 1975. Cantes flamencos. Madrid: Cultura Hispánica. (1 $1^{\mathbf{a}}$ ed. de 1881).

Manual del baratero o arte de manejar la navaja, el cuchillo y la tijera de los jitanos. M. D. R. (del autor sólo se conocen las iniciales). Madrid: Heliodoro. (Edición facsimilar de la de 1849, n. 3 de la colección "Gitanismo").

MARTíneZ DEL PERAl ForTón, RAfael. 1979. La navaja española antigua. Cáceres: Gladius.

MÉNDEZ, CARMEN. 2002. "Los gitanos, entre el silencio y la desigualdad". El Noticiero de las ideas 11: 33-37. 
MISTRAL, FRÉDÉRIC. 1966. Lou Tresor dóu Felibrige ou Dictionnaire Provençal-Français. Osnabrück: Biblio.

Nueva Enciclopedia Larousse. Barcelona: Planeta. tomo IV

PAlACio ATARD, Vicente. 1964. Los españoles de la Ilustración. Madrid: Guadarrama.

PARKER, GEOFFREY. 1978. Het Spaanse leger in de lage landen. Haarlem: Fibula-Van Dishoeck.

-. 1999. "De politieke wereld van Karel V", en Karel V 1500-1558 De Keizer en zijn tijd: 113-226. Amberes: Mercatorfonds.

Rico Y SINOBAS, MANUEL. 1871. Noticia bistórica de la cuchillería y de los cuchilleros antiguos en España. Madrid: Rivadeneyra.

RodrígueZ MARín, Francisco. 1883. Cantos populares españoles. Sevilla: Álvarez y Ca. ROPERO NÚÑEz, Miguel. 1978. El léxico caló en el lenguaje del cante flamenco. Sevilla: Universidad de Sevilla.

SAlAZAR, Adolfo. 1961. La música en Cervantes y otros ensayos. Madrid: Ograma.

SAlES MAYO, FRANCISCO DE. 1979. El gitanismo. Historia, costumbres y dialecto de los gitanos. Madrid: Heliodoro. (Edición facsimilar de la de 1870, n. 1 de la colección "Gitanismo")

SALILlAS, RAFAel. 1896. El delincuente español. El lenguaje. Madrid: Victoriano Suárez. SHIPLEY, JOSEPH T 1945. Dictionary of word origins. Nueva York: Greenwood Press.

STOLS, EDDY. 1971. De Spaanse Brabanders of de handelsbetrekkingen der Zuidelijke Nederlanden met de Iberische wereld 1598-1648. Bruselas: Paleis der Academieën.

- 1972. "Bronnen voor de geschiedenis van de Zuidnederlandse handel met Spanje en Portugal (15de-18de eeuw)", Economische geschiedenis van België: Handelingen van bet Colloquium te Brussel, 17-19 november 1971: 374-385. Bruselas: Cultura.

StroOBANTS, AIMÉ. 1991. "De Antwerpse wapenmakers en hun privileges". Militaria Belgica: 3-32.

TeRlinden, ChARLES. 1965. Keizer Karel de Viffde. Brujas-Utrecht: Desclée De Brouwer.

TORRIONE, MARgARITA. 1992. "Del viajero ilustrado al viajero romántico. Visión del folclore gitano-andaluz". Cuadernos hispanoamericanos, Los Complementarios 9-10: Los intelectuales ante el flamenco: 9-30.

Trésor de la langue française. 1980. París: Centre National de la Recherche Scientifique. Tomo 8. 